Esophageal er osi on as a possi bl e bacteri al ent ry si te in an acute I ymphobl ast i c I eukemia pat i ent with sepsi $s$

\begin{tabular}{|l|l|}
\hline 著者 & $\begin{array}{l}\text { I kegaya Sat oshi, Yoshi da Aki ra, I wasaki } \\
\text { H rom chi, Nai ki Hi r onobu, Ueda Takanori }\end{array}$ \\
\hline $\begin{array}{l}\text { j our nal or } \\
\text { publ i cat i on ti t I e }\end{array}$ & I nt er nat i onal J our nal of Henat ol ogy \\
\hline vol une & 77 \\
\hline number & 4 \\
\hline page range & $395-398$ \\
\hline year & $2003-05$ \\
\hline URL & ht t p: //hdl . handl e. net /10098/7686 \\
\hline
\end{tabular}




\title{
Esophageal Erosion as a Possible Bacterial Entry Site in an Acute Lymphoblastic Leukemia Patient with Sepsis
}

\author{
Satoshi Ikegaya, ${ }^{\text {a }}$ Akira Yoshida, ${ }^{\mathrm{b}}$ Hiromichi Iwasaki, ${ }^{\mathrm{c}}$ Hironobu Naiki, ${ }^{\mathrm{a}}$ \\ Takanori Ueda ${ }^{\mathrm{b}}$ \\ ${ }^{a}$ Second Department of Pathology, ${ }^{b}$ First Department of Internal Medicine, and ${ }^{c}$ Division of Transfusion Medicine, \\ Fukui Medical University, Fukui, Japan
}

\begin{abstract}
A 69-year-old man with relapsed acute lymphoid leukemia was treated with adriamycin, vincristine, and prednisolone. During this chemotherapy, the patient developed sepsis and meningitis. Although many kinds of antimicrobial drugs, including imipenem, meropenem, amphotericin-B, and $\gamma$-globulin were administered, the patient died of respiratory failure. A positive result for Enterococcus faecalis was obtained in both blood and cerebrospinal fluid culture. Autopsy revealed multiple small erosions in the lower esophagus. Histopathological examination showed multiple nuclear inclusion bodies of herpes simplex virus in the squamous epithelial cells at the edge of the erosions. Moreover, proliferation of micrococci was observed at the base of the erosions and in the lumina of the submucosal small vessels. These findings suggested that $E$ faecalis entered the blood circulation from this lesion. In many patients with febrile neutropenia, the pathogenesis of infection remains unclear. Our case seems significant for clarifying the focus and pathogenesis of febrile neutropenia.
\end{abstract}

Key words: Entry site; Sepsis; Esophageal erosion; Leukemia; Enterococcus faecalis

\section{Introduction}

It is widely known that infectious diseases often are caused by various pathogens during neutropenia (neutrophil count $<500 / \mu \mathrm{L}$ ). In particular, when the neutrophil count is less than $100 / \mu \mathrm{L}$, fatal infectious diseases may develop [1]. During neutropenia, the pathogen cannot be identified in many cases in spite of several blood culture tests [2]. Antibiotics usually are administered empirically, without the results of culture tests, as soon as the patient becomes febrile.

Because the pathogenesis of febrile neutropenia has not been clarified, evaluation of pathogenesis by autopsy may be significant. This report describes our use of autopsy to investigate the entry site of Enterococcus faecalis, which was the pathogen of sepsis and meningitis during neutropenia in a patient with acute lymphoblastic leukemia.

Correspondence and reprint requests: Satoshi Ikegaya, Second Department of Pathology, Fukui Medical University, 23-3 Shimoaizuki, Matsuoka-cho, Yoshida-gun, Fukui 910-1193, Japan; 81-0776-61-3111 (ext 2237); fax: 81-0776-61-8123.

\section{Case Report}

A 69-year-old Japanese man with pneumonia was referred to our hospital because his white blood cell (WBC) count increased to $12,400 / \mu \mathrm{L}$, including $80 \%$ blast cells, on January 4, 1999. Respiratory sound was attenuated in the right lower lung, the liver and spleen were not palpable, and superficial lymph nodes were not swollen.

Small lymphoblasts showing a high nuclear cytoplasmic ratio and negative peroxidase staining were recognized, and the diagnosis made was acute lymphoblastic leukemia (ALL) L1 by French-American-British criteria. The surface markers of blasts showed positive CD10, CD19, KORSA3544 [3], and HLA-DR. Chromosomal analysis revealed a normal karyotype $(46, \mathrm{XY})$.

Pneumonia was treated with cefpirome $2 \mathrm{~g} /$ day and granulocyte colony-stimulating factor $150 \mu \mathrm{g} /$ day intravenously. Antileukemic chemotherapy was administered from January 28,1999 , according to the treatment protocol of the Japan Adult Leukemia Study Group ALL97.

Complete remission was achieved after induction chemotherapy, but the patient had a relapse after 3 courses of consolidation therapy.

The patient was treated with 4 courses of reinduction chemotherapy; however, remission was not achieved, and 


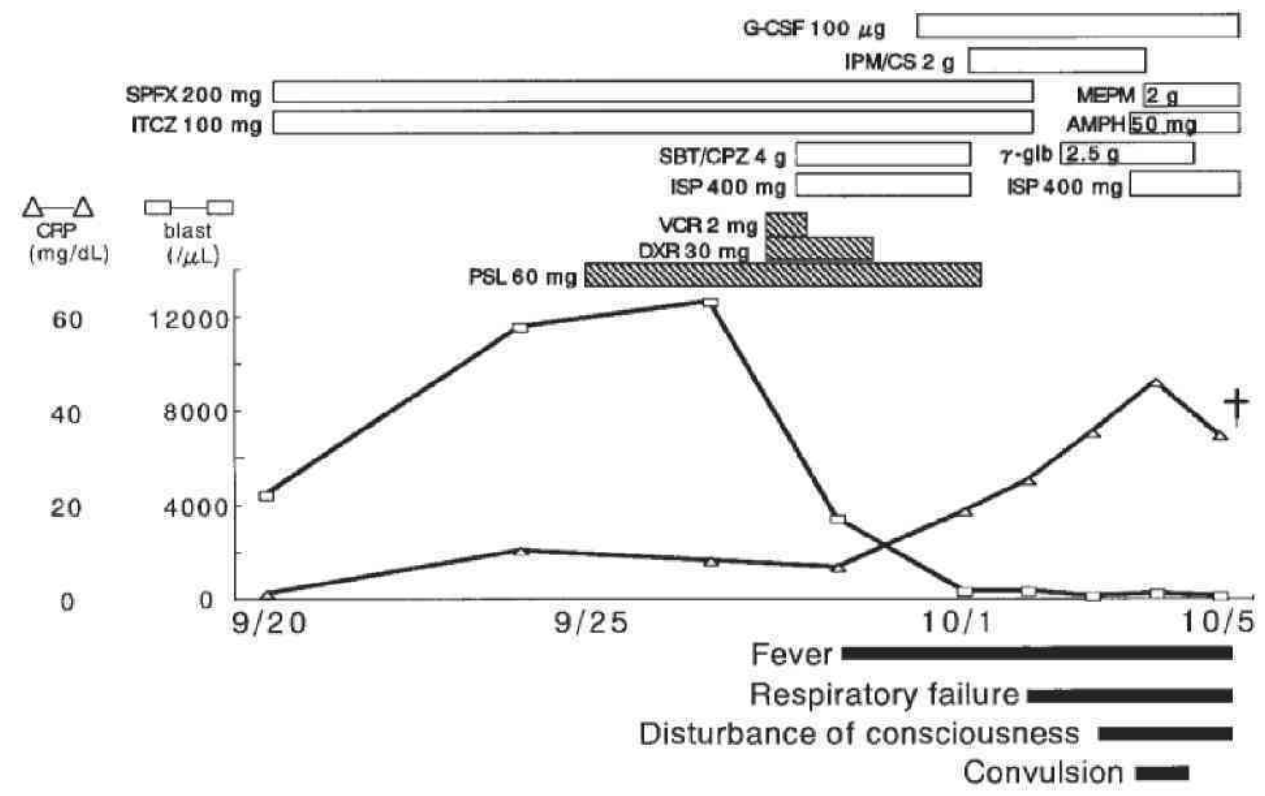

Figure 1. Clinical course. G-CSF indicates granulocyte colony-stimulating factor; IPM/CS, imipenem/cilastatin; SPFX, sparfloxacin; MEPM, meropenem; ITCZ, itraconazole; AMPH, amphotericin B; SBT/CPZ, sulbactam/cefoperazone; $\gamma$-glb, $\gamma$-globulin; ISP, isepamicin; CRP, C-reactive protein; VCR, vincristine; DXR, adriamycin; PSL, prednisolone.

the peripheral blood lymphoblast cell count increased from September 20, 1999. Peripheral blood counts were as follows: $\mathrm{WBC}, 4400 / \mu \mathrm{L}$ (lymphocytes, $11 \%$; myelocytes, $1 \%$; and lymphoblasts, $88 \%$ ); hemoglobin, $7.3 \mathrm{~g} / \mathrm{dL}$; and platelets, $17,000 / \mu \mathrm{L}$. The results of biochemical and coagulation tests revealed no abnormal findings except elevation of lactate dehydrogenase up to $1543 \mathrm{IU} / \mathrm{L}$ (normal range, 220 to $460 \mathrm{IU} / \mathrm{L}$ ). Combination chemotherapy, including adriamycin, vincristine, and prednisolone was administered beginning on September 28, 1999. The clinical course is shown in Figure 1.

Sparfloxacin $200 \mathrm{mg} /$ day and itraconazole $100 \mathrm{mg} /$ day were administered as prophylaxis for infection from September 20,1999, because the mature granulocyte count was $0 / \mu$ L. Leukemic cell numbers were significantly decreased by antileukemic chemotherapy, but the patient became febrile $\left(39.0^{\circ} \mathrm{C}\right)$ on September 29 . Immediately, sulbactam/cefoperazone $4 \mathrm{~g} /$ day and isepamicin $400 \mathrm{mg} /$ day were administered empirically. However, these antibiotics were not effective. C-reactive protein level increased to $18.4 \mathrm{mg} / \mathrm{dL}$ on October 1 , and respiratory insufficiency was observed from October 2, neither pathogen nor focus of infection having been identified by various clinical tests. Convulsions and disturbance of consciousness occurred on October 3. Lumbar puncture was performed on suspicion of meningitis. Cerebrospinal fluid (CSF) pressure was $18 \mathrm{~cm} \mathrm{H}_{2} \mathrm{O}$, and the cell count was $10^{3} / \mathrm{mL}$. All leukocytes in the CSF were mononuclear. Although many kinds of antimicrobial drugs were administered, the patient died of respiratory failure on October 5 .

$E$ faecalis was detected in cultures of blood and CSF obtained on October 2 and October 4, respectively. Both E faecalis specimens showed the same drug sensitivities. Sputum obtained from the right second carina during autopsy was cultured. In this microbial examination Enterococcus faecium, not E faecalis, was detected (Table 1). Surveillance culture results were positive for Enterococcus species in the stool and $\alpha$-Streptococcus in the pharynx.

Autopsy revealed multiple small erosions in the lower esophagus. Histopathological examination showed multiple nuclear inclusion bodies of herpes simplex virus (HSV) in the squamous epithelial cells at the edge of the erosions. Moreover, proliferation of micrococci was observed at the base of the erosions and in the lumina of submucosal small vessels. Diffuse dispersing microabscesses were recognized in the cortex of the kidney and cardiac muscles. It was concluded that $E$ faecalis entered the blood circulation from this lesion to the systemic body (Figure 2). No infectious pathogen was recognized in the lungs, but diffuse alveolar

Table 1.

Drug Sensitivity of Bacteria from Positive Culture Tests*

\begin{tabular}{llcl}
\hline Materials: & Blood & Cerebrospinal Fluid & Sputum \\
\hline Date: & $10 / 2 / 1999$ & $10 / 4 / 1999$ & $10 / 5 / 1999$ \\
\hline Bacterium: & E faecalis & E faecalis & E faecium \\
\hline \multicolumn{4}{c}{ Minimum Inhibitory Concentration } \\
\cline { 2 - 4 } Sensitivity & \multicolumn{3}{c}{} \\
Penicillin G & $\mathrm{S} 8$ & $\mathrm{~S} 8$ & $\mathrm{R}>8$ \\
Ampicillin & $\mathrm{S} 2$ & $\mathrm{~S} 2$ & $\mathrm{R}>8$ \\
Piperacillin & $\mathrm{S}<16$ & $\mathrm{~S}<16$ & $\mathrm{R}>64$ \\
Erythromycin & $\mathrm{R}>4$ & $\mathrm{R}>4$ & $\mathrm{R}>4$ \\
Minocycline & $\mathrm{S} 4$ & $\mathrm{~S} 4$ & $\mathrm{~S} 2$ \\
Imipenem & $\mathrm{S} 2$ & $\mathrm{~S} 2$ & $\mathrm{R}>8$ \\
Vancomycin & $\mathrm{S}<2$ & $\mathrm{~S}<2$ & $\mathrm{~S}<2$ \\
Levofloxacin & $\mathrm{R}>4$ & $\mathrm{R}>4$ & $\mathrm{R}>4$ \\
\hline
\end{tabular}

${ }^{*} E$ indicates Enterococcus; $\mathrm{S}$, susceptibility; $\mathrm{R}$, resistance. 

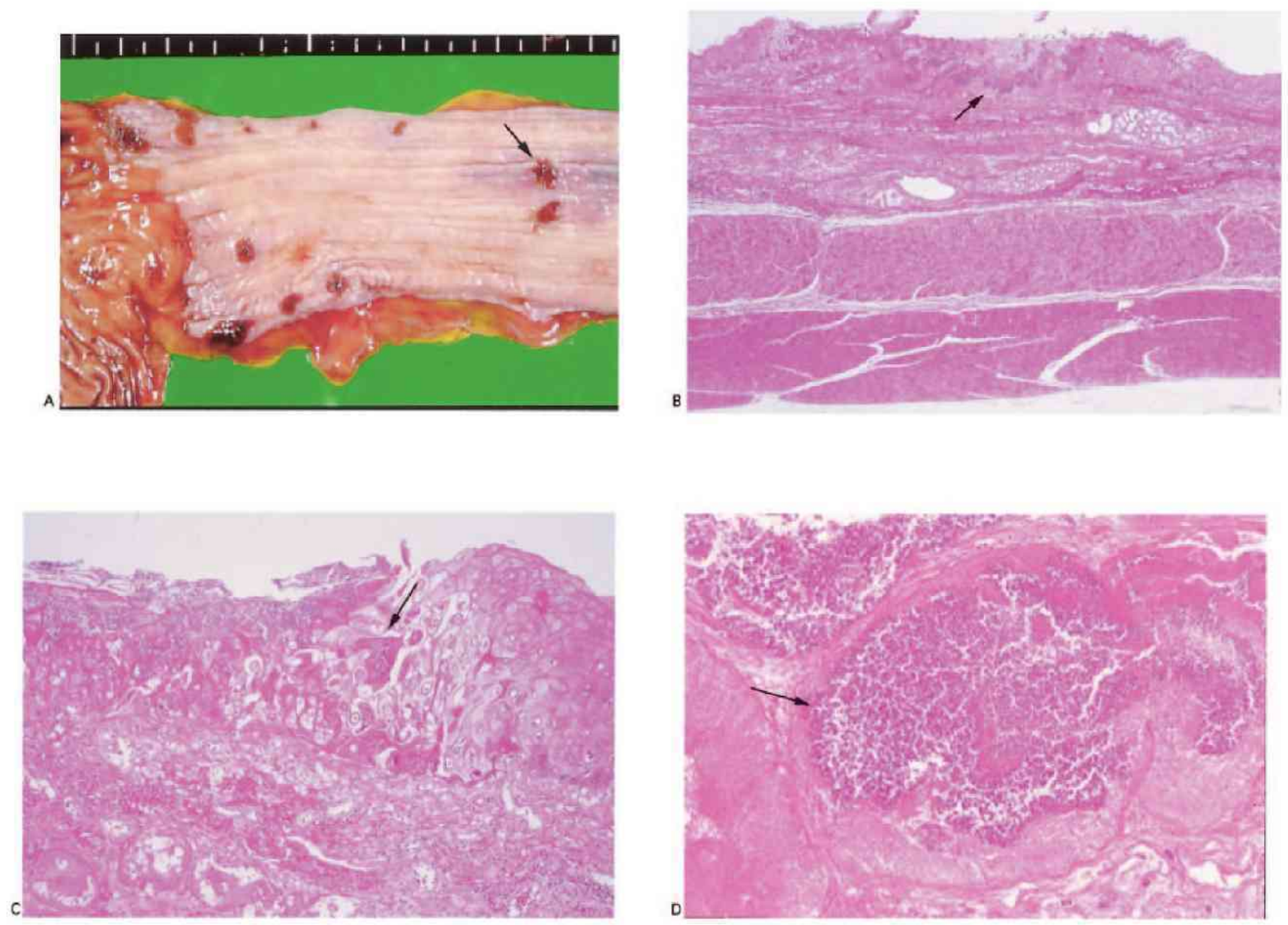

Figure 2. Esophageal erosion detected by autopsy (original magnification $\mathrm{A}, \times 1 ; \mathrm{B}, \times 5 ; \mathrm{C}, \times 25 ; \mathrm{D}, \times 100$ ). Arrows indicate multiple erosions in the lower esophagus (A), proliferation of micrococei at the base of erosions (B), multiple nuclear bodies of herpes simplex virus (C), and micrococei in the lumina of submucosal vessels (D).

damage with hyalinization was observed, and it is assumed that acute respiratory distress syndrome occurred. No infectious focus was recognized in the stomach or gut.

\section{Discussion}

Intensive antileukemic chemotherapy has resulted in high remission-induction rates for patients with acute leukemia, whereas myelosuppression, the main toxic effect of intensive therapy, directly causes infectious disease [4].

Fever in neutropenic patients (neutrophil count, $<500 / \mu \mathrm{L}$ or $<1000 / \mu \mathrm{L}$ with a predicted decline to $\leq 500 / \mu \mathrm{L}$ ) was defined as febrile neutropenia by the Infectious Diseases Society of America (IDSA) in 1997 [5]. In general, the entry site of bacteria often is uncertain even after the pathogen has been identified by blood culture. In our case, both sepsis and meningitis were caused by the same $E$ faecalis. We observed multiple nuclear inclusion bodies of HSV at the edge of the erosions and proliferation of micrococci at the base of the erosions and in the lumina of submucosal small vessels in the lower esophagus. No entry site of bacteria was recognized in the stomach, gut, bronchus mucosa, lungs, urinary tract, skin, or oral membrane. Therefore it is reasonable to consider that $E$ faecalis may have entered via esophageal erosions caused by HSV infection.

To our knowledge there has been no report identifying esophageal erosion as a bacterial entry site in a patient with sepsis, but esophageal erosion by a virus was recognized in $13 \%$ of all autopsy cases in our hospital from 1998 to 2000 (unpublished observation). Moreover, the frequency increases to $25 \%$ when limited to hematological diseases. Becker et al reported that the frequency of esophagitis caused by HSV is $0.5 \%$ to $6 \%$ in unselected patients [6]. However, to our knowledge there have been no reports that HSV infection may be a cause of $E$ faecalis septicemia.

Guidelines from the US Centers for Disease Control and Prevention recommend preventive administration of acyclovir to HSV antibody-positive patients receiving hematopoietic stem cell transplants, but there is no consensus protocol in the case of conventional antileukemic chemotherapy. The intensity of antileukemic chemotherapy has increased in recent years. Prophylaxis for viral infection should now be considered, especially for patients with lymphoid malignancy treated with intensive chemotherapy. 
In a previous study, gram-negative rod infection was frequently observed during neutropenia. Pseudomonas aeruginosa, in particular, has a high mortality rate as a pathogen [7]. Monotherapy with a cephem or carbapenem, and combination therapy with an antipseudomonal cephem and aminoglycoside are recommended in the febrile neutropenia guideline of the IDSA [5]. In this case antibiotics were selected according to these guidelines. However, it has been reported that the frequency of gram-positive bacterial infection has increased in recent years $[8,9]$. Several $\beta$-lactam antibiotics were administered to our patient. However, there was no improvement. Therefore it is also necessary to consider administration of vancomycin in the case of gram-positive bacterial infections.

Until now, in many cases of febrile neutropenia, the exact pathogenesis of infection has remained unclear. It is important to investigate by autopsy the entry site of bacterial infection. Thus our case seems significant for clarifying the focus and pathogenesis of febrile neutropenia.

\section{References}

1. Balducci L, Haldrook JC, Morrison FS, et al. Acute leukemia and infections: perspectives from a general hospital. Am J Hematol. 1983;15:57-63.

2. Pennington JE. Fever neutropenia and malignancy: a clinical syndrome in evolution. Cancer. 1977;39:1345-1349.
3. Mori T, Sugita K, Suzuki T, et al. A novel monoclonal antibody, KOR-SA3544, which reacts to Philadelphia chromosome-positive acute lymphoblastic leukemia cells with high sensitivity. Leukemia. 1995;9:1233-1239.

4. Iwasaki H, Misaki H, Nakamura T, Ueda T. Surveillance of the serum Candida antigen titer for initiation of antifungal therapy after post-remission chemotherapy in patients with acute leukemia. Int J Hematol. 2000;71:266-272.

5. Hughes WT, Armstrong D, Bodey GP, et al. 1997 guidelines for the use of antimicrobial agents in neutropenic patients with unexplained fever. Infectious Diseases Society of America. Clin Infect Dis. 1997;25:551-573.

6. Becker K, Lubke HJ, Borchard F, Haussinger D. Inflammatory esophageal diseases caused by herpes simplex virus infections: overview and report of 15 personal cases. Z Gastroenterol. 1996;34: 286-295.

7. Yokota T, Teshima H, Okajima Y, et al. Septicemia associated with hematopoietic disorders and its features according to respective primary disorders. Kansenshogaku Zasshi. 1996;70: 108-115.

8. De Pauw BE, Donnelly JP. Infection in the immunocompromised host: general principles. In: Mandell GL, Bennett JE, Dolin R, eds. Principles and Practice of Infectious Disease. 5th ed. Philadelphia: Churchill Livingstone; 2000:3079-3090.

9. Horiuchi A, Hasegawa H, Masaoka T, et al. Actual conditions of bacterial infection associated with hematopoietic disorders: changes in 10 years. Hanshin Study Group of Hematopoietic Disorders and Infections. Kansenshogaku Zasshi. 1990;64:299-309. 